\title{
Analisis Perencanaan Dan Pengadaan Obat Antibiotik Berdasarkan Metode ABC Indeks Kritis Di Instalasi Farmasi Rumah Sakit Advent Manado
}

\author{
Widya Astuty Loloa*, Weny Indayany Widodoa, Deby Afriani Mpilaa, \\ aProgram Studi Farmasi, FMIPA, Unsrat, Manado, Indonesia
}

K A T A K U N I

Perencanaan

Pengadaan

Analisis ABC Indeks Kritis Antibiotik)

\begin{abstract}
A B S T R A K
Perencanaan dan pengadaan obat merupakan salah satu fungsi penting dalam tahapan manajemen logistik obat, termasuk obat antibiotik. Sistem pengelolaan yang baik akan menjamin tersedianya obat sesuai dengan kebutuhan pasien. Analisis ABC Indeks Kritis dapat digunakan untuk menentukan prioritas obat yang akan diadakan. Penelitian ini bertujuan untuk menganalisis perencanaan dan pengadaan obat antibiotik di Instalasi Farmasi Rumah Sakit Advent Manado menggunakan analisis ABC Indeks Kritis. Penelitian ini merupakan penelitian deskriptif kuantitatif. Data primer diperoleh dari 8 orang responden yang mengisi kuesioner dan data sekunder diperoleh dari Instalasi Farmasi, Bagian Logistik dan Bagian Keuangan. Data yang diperoleh dianalisis dengan metode $A B C$ Indeks Kritis. Hasil penelitian menunjukkan bahwa dari total 63 item obat antibiotik, 6 item merupakan kelompok A (9,52\%), 29 item merupakan kelompok B (46,03\%), dan 28 item merupakan kelompok C (44,44\%). Metode ABC Indeks Kritis dapat membantu rumah sakit dalam melakukan perencanaan dan pengadaan obat secara efisien dengan mempertimbangkan nilai pakai, nilai investasi dan nilai kritis obat.

A B S T R A C T

Drug planning and procurement is one of the most important function in steps of logistics management, include antibiotic drugs. A good management system will ensure the medical availability of drugs according to patient needs. The ABC critical index analysis can be used to prioritize drug procurement. This study aim to analyze the planning and procurement of antibiotic drugs in Pharmacy Installation at Manado Adventist Hospital by using ABC critical index analysis. The design of this research was quantitative descriptive study. Primary data were obtained from 8 respondents who filled the questionnaires; and secondary data were obtained from Pharmacy Installation, Logistic Division and Finance Division. Data were analyzed with $A B C$ critical index method. The result of $A B C$ critical index analysis showed that 63 antibiotic drug items were found, respectively, amounting for 6 (9.52\%), 29 (46.03\%) and 28 (44.44\%) of drug items were found to be category $A, B$ and $C$ items. ABC critical index method can help hospital drug management in order to planning and procurement the drug efficiently by considering the use value, investment value, and critical value of drug.
\end{abstract}

KE Y W OR D S

Planning

Procurement

ABC Critical Index Analysis Antibiotic

$\frac{\text { TERSEDIA ONLINE }}{01 \text { Februari } 2021}$

disebutkan bahwa pelayanan kefarmasian adalah suatu pelayanan langsung dan bertanggung jawab kepada pasien yang berkaitan dengan sediaan farmasi dengan maksud mencapai hasil yang pasti untuk meningkatkan mutu kehidupan pasien. 
Berkaitan dengan hal tersebut, diketahui bahwa pelayanan kefarmasian memegang peranan penting sebagai pelayanan penunjang sekaligus sebagai revenue center utama bagi rumah sakit. Hal ini disebutkan karena lebih dari 90\% pelayanan kesehatan yang berlangsung di rumah sakit menggunakan perbekalan farmasi, antara lain obatobatan, bahan kimia, bahan radiologi, bahan medis kesehatan habis pakai, alat kesehatan, dan gas medik. Pernyataan ini menunjukkan pentingnya melakukan pengelolaan perbekalan farmasi secara cermat dan bertanggung jawab agar terhindar dari masalah berupa kerugian bagi pihak rumah sakit (Suciati et al, 2006).

Masalah kekosongan obat di rumah sakit juga berdampak pada tidak terpenuhinya kebutuhan pasien akan terapi obat yang optimal. Antibiotik merupakan salah satu obat dengan persentase pemakain yang cukup tinggi dan alokasi dana yang besar. Antibiotik digunakan untuk mencegah dan mengobati penyakit - penyakit infeksi. Frekuensi pemakaian antibiotik yang tinggi tetapi tidak rasional dapat menimbulkan dampak negatif (Kartika et al, 2014). Di negara yang sudah maju 13-37\% dari seluruh penderita yang dirawat di rumah sakit mendapatkan antibiotik baik secara tunggal atau kombinasi, sedangkan di negara berkembang 30$80 \%$ penderita yang dirawat di rumah sakit mendapatkan antibiotik dan penggunaan antibiotik yang tidak rasional sangat banyak dijumpai baik di negara maju maupun berkembang. Hasil penelitian dari studi Antimicrobial Resistence in Indonesia (AMRIN study) tahun 2000 - 2004 menunjukkan bahwa terapi antibiotik diberikan tanpa indikasi di RSUP Dr. Kariadi Semarang sebanyak 20-53\% dan antibiotik profilaksis tanpa indikasi sebanyak 43 81\% (Amrin Study, 2005). Resistensi antibiotik adalah dampak paling merugikan akibat penggunaan antibiotik secara tidak rasional. Kerugian bagi pasien antara lain layanan pengobatan menjadi tidak efektif, terjadi peningkatan morbiditas maupun mortalitas, serta meningkatnya biaya perawatan kesehatan (Brahma, 2012).

Hasil wawancara yang dilakukan kepada kepala instalasi farmasi rumah sakit Advent Manado, diketahui bahwa perencanaan dan pengadaan obat masih dilakukan berdasaran kebutuhan dalam jangka pendek dengan melihat jumlah stok obat kosong atau hampir habis. Dengan kata lain, prosesnya menggunakan metode konsumsi yaitu berdasarkan penggunaan pada periode sebelumnya. Sering dilakukan pembelian obat yang tidak terencana dan dalam jumlah kecil mengakibatkan kegiatan pengelolaan menjadi tidak efisien. Sering kali dijumpai terjadi kekosongan obat yang berdampak pada tidak optimalnya pelayanan kefarmasian kepada pasien.

Beberapa hal yang menjadi penyebab pengelolaan obat yang tidak efisien diantaranya keterbatasan dana, sistem pencatatan stok obat yang belum memadai, serta penulisan resep yang tidak mengacu pada formularium rumah sakit.
Diperkitakan kurangnya sosialisasi ketersediaan obat di instalasi farmasi kepada dokter penulis resep merupakan salah satu penyebab beberapa obat yang tertulis dalam resep yang tidak tersedia di instalasi farmasi, sehingga sering kali perlu dilakukan konfirmasi kepada dokter penulis resep untuk memberikan alternatif obat lain yang tersedia.

Penelitan ini bertujuan untuk untuk melakukan analisis dengan metode ABC Indeks Kritis pada tahapan perencanaan dan pengadaan obat antibiotik di Instalasi Farmasi Rumah Sakit Advent Manado.

\section{Material dan Metode}

Penelitian ini merupakan jenis penelitian desktiptif kualitatif dengan mengumpulkan data hasil kuesioner dari dokter sebagai responden yang memiliki keterkaitan dengan penelitian yang dilakukan, yaitu dokter yang meresepkan antibiotik di rumah sakit Advent Manado. Adapun informasi lainnya diperoleh dari data di instalasi farmasi, bagian logistik dan bagian keuangan.

Efisiensi penggunaan dana rumah sakit untuk pengadaan obat tergantung pada kemampuan dalam pengelolaannya, terutama pada tahapan perencanaan dan pengadaan obat. Pemilihan metode yang tepat dapat membantu tercapainya pengelolaan obat yang baik. Analisis perencanaan dan pengadaan obat dengan menggunakan metode $A B C$ Indeks Kritis merupakan salah satu pilihan yang dapat diterapkan. Metode ini dapat membantu menentukan kelompok obat yang mejadi prioritas untuk diadakan sesuai dengan dana yang tersedia dan berdasarkan dampaknya terhadap kesehatan. Dapat dipertimbangkan apakah kelompok obat tersebut termasuk vital, esensial, atau nonesensial bagi pasien (Febriawati, 2013).

Tahapan analisis data dengan metode ABC Indeks Kritis ialah sebagai berikut:

1. Menghitung Nilai Pakai

- Menghitung total pemakaian obat.

- Data pemakaian obat dikelompokkan berdasarkan jumlah pemakaian. Diurutkan dari pemakaian terbesar sampai yang terkecil.

- Kelompok A dengan pemakaian 70\% dari keseluruhan pemakaian obat.

- Kelompok B dengan pemakaian 20 \% dari keseluruhan pemakaian obat.

- Kelompok C dengan pemakaian 10 \% dari keseluruhan pemakaian obat.

2. Menghitung Nilai Investasi

- Menghitung total investasi setiap jenis obat.

- Dikelompokkan berdasarkan nilai investasi obat. Diurutkan dari nilai investasi terbesar sampai yang terkecil.

- Kelompok A dengan nilai investasi 70\% dari total investasi obat.

- Kelompok B dengan nilai investasi 20 \% dari total investasi obat.

- $\quad$ Kelompok C dengan nilai investasi $10 \%$ dari total investasi obat.

3. Menentukan Nilai Kritis Obat

- Menyusun kriteria nilai kritis obat.

- Membagikan kuesioner berupa daftar obat kepada dokter untuk mendapatkan nilai kritis 
obat, dengan kriteria yang telah ditentukan. Dokter yang mengisi kuesioner tersebut adalah dokter yang berpengaruh terhadap peresepan dan pemakaian obat.

Kuesioner ini bertujuan untuk mendapatkan nilai kritis obat. Hasil yang diperoleh selanjutnya dianalisis dengan tahapan sebagai berikut:

- Lakukan survei tentang kekritisan obat terhadap dokter yang sering menulis resep.

- Buat rata-rata skor dari setiap jenis obat.

- Susun tabel obat dari skor tertinggi hingga skor terendah.

- Cek persentase (\%) kumulatif, potong \% kumulatif menjadi 70\% untuk kelompok X, 20\% kelompok Y, dan 10\% kelompok Z.

Kriteria nilai kritis obat adalah:

- Kelompok X atau kelompok obat vital, adalah kelompok obat yang sangat esensial atau vital untuk memperpanjang hidup, untuk mengatasi penyakit penyebab kematian ataupun untuk pelayanan pokok kesehatan. Kelompok ini tidak boleh terjadi kekosongan.

- Kelompok Y atau kelompok obat esensial adalah obat yang bekerja kausal yaitu obat yang bekerja pada sumber penyebab penyakit, logistik farmasi yang banyak digunakan dalam pengobatan penyakit terbanyak. Kekosongan obat kelompok ini dapat ditolerir kurang dari 48 jam.

- Kelompok Z atau kelompok obat nonesensial, adalah obat penunjang agar tindakan atau pengobatan menjadi lebih baik, untuk kenyamanan atau untuk mengatasi keluhan. Kekosongan obat kelompok ini dapat ditolerir lebih dari 48 jam.

4. Menentukan Nilai Indeks Kritis (NIK) Obat Untuk memperoleh NIK obat, digunakan persamaan sebagai berikut:

NIK = Nilai Pakai + Nilai Investasi $+(2 \times$ Nilai Kritis)

5. Mengelompokkan obat ke dalam kelopok A, B, dan $\mathrm{C}$ dengan kriteria:

- Kelompok A dengan NIK 9,5 - 12

- Kelompok B dengan NIK 6,5 - 9,4

- Kelompok C dengan NIK 4 - 6,4

Kelompok A dengan NIK tertinggi yaitu 12, mempunyai arti bahwa obat tersebut adalah obat dalam kategori kritis bagi sebagian besar pemakainya, atau bagi satu atau dua pemakain, tetapi juga mempunyai nilai investasi dan turn over yang tinggi.

\section{Hasil dan Pembahasan}

Perencanaan dan pengadaan obat di instalasi farmasi rumah sakit Advent Manado dilakukan oleh bagian logistik berkoordinasi dengan instalasi farmasi serta bagian keuangan rumah sakit. Ketersediaan dana merupakan salah satu faktor penting dalam menunjang keberlangsungan pengelolaan logistik yang baik. Dana yang terbatas dapat diatasi dengan menerapkan metode perencanaan dan pengadaan yang tepat. Salah satunya ialah dengan menggunakan metode $A B C$ Indeks Kritis. Pada metode ini dapat diketahui pengelompokkan obat selain dari nilai ekonomi, juga berdasarkan nilai kritis obat tersebut yaitu prioritas obat mana yang lebih penting untuk diadakan dibandingkan obat yang lain, dimana data ini diperoleh dari hasil kuesioner kepada dokter panulis resep.

Daftar obat pada kuesioner merupakan daftar obat yang diperoleh dari bagian logistik farmasi dan tercatat secara komputerisasi. Data tersebut bersumber dari data pemakaian obat. Akan tetapi, pada saat pengambilan data beberapa responden menyampaikan bahwa obat yang tertera dalam daftar kuesioner tidak tersedia di rumah sakit tersebut. Ketidaktahuan dokter mengenai keberadaan obat tersebut kemungkinan karena kurangnya sosialisasi dari bagian instalasi farmasi dan bagian logistik obat. Hal ini berdampak pada penulisan obat yang tidak tersedia di instalasi farmasi atau dengan kata lain stok obat dianggap kosong. Disamping itu, dapat terjadi penumpukkan obat yang tidak diresepkan oleh dokter. Kelebihan stok obat juga akan merugikan pihak rumah sakit. Kerugian dapat berupa penumpukkan persediaan obat yang memerlukan kapasistas tempat penyimpanan yang lebih besar, diperlukan tenaga tambahan untuk mengelola obat tersebut, serta semakin banyak obat yang kemungkinan tidak terpakai hingga melewati batas masa kedaluwarsanya.

Analisis perencanaan dan pengadaan obat antibiotik di instalasi farmasi rumah sakit Advent Manado menggunakan data pemakaian obat periode Januari Desember 2019. Berdasarkan hasil analisis dengan metode ABC Indeks Kritis, diperoleh hasil berikut.

\section{a. Nilai Pakai}

Pengelompokkan obat berdasarkan nilai pemakaian diperoleh data sebagai berikut.

Kelompok A : 4 item (6,35\%) dari total item obat antibiotik dengan jumlah pemakaian $127.360(63,48 \%)$ dari jumlah pemakaian seluruhnya.

Kelompok B : 4 item (6,35\%) dari total item obat antibiotik dengan jumlah pemakaian 47.107 (23,48\%) dari jumlah pemakaian seluruhnya.

Kelompok C : 55 item (87,30\%) dari total item obat antibiotik dengan jumlah pemakaian 26.166 (13,04\%) dari jumlah pemakaian seluruhnya.

Hasil tersebut dapat dilihat pada Tabel 1 berikut.

Tabel 1. Pengelompokkan Obat dengan Analisis ABC Berdasarkan Nilai Pakai

\begin{tabular}{ccccc}
\hline Kelompok & $\begin{array}{c}\text { Jumlah } \\
\text { Item } \\
\text { Obat }\end{array}$ & $\begin{array}{c}\text { Persentase } \\
\text { (\%) }\end{array}$ & $\begin{array}{c}\text { Jumlah } \\
\text { Pemakaian }\end{array}$ & $\begin{array}{c}\text { Persentase } \\
(\%)\end{array}$ \\
\hline A & 4 & 6,35 & 127.360 & 63,48 \\
B & 4 & 6,35 & 47.107 & 23,48 \\
C & 55 & 87,30 & 26.166 & 13,04 \\
\hline Jumlah & 63 & 100 & $\mathbf{2 0 0 . 6 3 3}$ & 100 \\
\hline
\end{tabular}


Data nilai pakai obat disajikan untuk memberikan gambaran jumlah item obat selama periode 1 (satu) tahun beserta jumah pemakaiannya. Data tersebut memperlihatkan bahwa kelompok $A$ dan $B$ dengan jumlah item obat yang sedikit, namun jumlah pemakaian yang lebih tinggi. Sebaliknya pada kelompok C, jumlah item obat cukup banyak, tetapi jumlah pemakaian sedikit. Hasil penelitian ini sejalan dengan hasil penelitian yang dilakukan oleh Suciati et al (2006), dimana pada nilai pakai persentase jumlah item kelompok obat $\mathrm{A}, \mathrm{B}$, dan $\mathrm{C}$ berbanding terbalik dengan persentase jumlah pemakaiannya. Jumlah item obat sedikit, tetapi persentase pemakaian lebih tinggi. Pada penelitian tersebut, diperoleh data nilai pakai pada kategori jumlah item obat dan persentase jumlah pemakaian untuk kelompok $\mathrm{A}, \mathrm{B}$, dan $\mathrm{C}$ secara berturutturut yaitu 124 item obat (69,10\%), 176 item obat $(21,04 \%)$ dan 707 item obat (9,86\%). Banyaknya item obat yang termasuk dalam kelompok $\mathrm{C}$ disebabkan karena terdapat item obat yang ditemukan tersedia dalam beberapa nama dagang, namun dengan kandungan bahan aktif yang sama. Dampaknya ialah pilihan item obat terlalu banyak bagi dokter penulis resep. Merujuk pada kriteria dalam pemilihan obat, salah satunya yaitu memilih jenis obat seminimal mungkin dengan cara menghindari kesamaan jenis. Tujuannya yaitu untuk menentukan prioritas perbekalan farmasi yang akan diadakan.

\section{b. Nilai Investasi}

Berdasarkan nilai investasi, diperoleh data dengan pengelompokkan sebagai berikut.

Kelompok A : 7 item (11,11\%) dari total item obat antibiotik dengan nilai investasi sebesar Rp.496.535.650 (69,49\%) dari nilai investasi seluruhnya.

Kelompok B : 9 item (14,29\%) dari total item obat antibiotik dengan nilai investasi sebesar Rp.144.751.640 (20,26\%) dari nilai investasi seluruhnya.

Kelompok C : 47 item (74,60\%) dari total item obat antibiotik dengan nilai investasi sebesar Rp.73.298.665 (10,26\%) dari nilai investasi seluruhnya.

Hasil pengelompokkan dapat dilihan pada Tabel 2.

Tabel 2. Pengelompokkan Obat dengan Analisis ABC Berdasarkan Nilai Investasi

\begin{tabular}{ccccc}
\hline Kelompok & $\begin{array}{c}\text { Jumlah } \\
\text { Item } \\
\text { Obat }\end{array}$ & $\begin{array}{c}\text { Persentase } \\
\text { (\%) }\end{array}$ & $\begin{array}{c}\text { Jumlah } \\
\text { Investasi } \\
\text { (Rp) }\end{array}$ & $\begin{array}{c}\text { Persentase } \\
\text { (\%) }\end{array}$ \\
\hline A & 7 & 11,11 & 496.535 .650 & 69,49 \\
B & 9 & 14,29 & 144.751 .640 & 20,26 \\
C & 47 & 74,60 & 73.298 .665 & 10,26 \\
\hline Jumlah & 63 & 100 & 714.585 .955 & 100 \\
\hline
\end{tabular}

Ketersediaan dana merupakan pertimbangan utama dalam perencanaan dan pengadaan obat.
Dengan dana yang terbatas, tahapan analisis ini merupakan salah satu pilihan yang tepat untuk menentukan prioritas obat yang lebih dahulu diadakan. Kelompok A merupakan kelompok obat yang menyerap dana terbesar dengan nilai investasi $69,49 \%$ dari nilai investasi seluruhnya. Diikuti oleh kelompok B dan kelompok C dengan kategori total investasi secara berturut-turut semakin kecil. Kelompok obat dengan nilai investasi tinggi dalam pengendaliannya perlu dikontrol secara berkala. Jumlah persediaan diharapkan seminimal mungkin dengan frekuensi pembelian yang lebih sering. Hindari kekosongan persediaan dengan memperhatikan kerja sama yang baik dengan pihak supplier, agar pengadaan obat dilakukan tepat waktu. Hal ini dilakukan untuk menghindari kerugian akibat penumpukkan item obat dengan nilai investasi yang tinggi. Dibutuhkan koordinasi yang baik dalam pengelolaan obat termasuk dokter penulis resep dalam mengoptimalkan penggunaan obat tersebut.

\section{c. Nilai Kritis}

Hasil pengelompokkan berdasarkan nilai kritis obat ialah sebagai berikut.

Kelompok $X \quad: 1$ item (1,59\%) dari total item obat

Kelompok $Y \quad: 53$ item (84,13\%) dari total item obat Kelompok Z : 9 item (14,29\%) dari total item obat

Pengelompokkan berdasarkan nilai kritis dapat dilihat pada Tabel 3.

Tabel 3. Pengelompokkan Obat Berdasarkan Nilai Kritis Obat

\begin{tabular}{ccc}
\hline Kelompok & $\begin{array}{c}\text { Jumlah } \\
\text { Item Obat }\end{array}$ & $\begin{array}{c}\text { Persentase } \\
(\%)\end{array}$ \\
\hline $\mathrm{X}$ & 1 & 1,59 \\
Y & 53 & 84,13 \\
$\mathrm{Z}$ & 9 & 14,29 \\
\hline Jumlah & 63 & 100 \\
\hline
\end{tabular}

Nilai kritis obat dimaksudkan untuk mengetahui pertimbangan responden yaitu dokter penulis resep tentang tingkat kekritisan obat berhubungan dengan dampaknya terhadap keselamatan dan kesehatan pasien. Penilaian responden dapat bervariasi tergantung pandangannya terhadap kemanfaatan obat tersebut. Beberapa item obat tersedia dalam merek dagang bahkan ditemukan item obat dengan bahan aktif yang sama, namun tersedia dalam beberapa merek dagang. Dampaknya bisa berupa hasil penilaian yang tidak konsisten.

\section{d. Nilai Indeks Kritis}

Berdasarkan perhitungan yang dilakukan, diperoleh hasi sebagai berikut.

Kelompok A : dengan NIK 9.5 - 12, sebanyak 6 item obat $(9,52 \%)$ dari total item obat.

Kelompok B : dengan NIK 6.5 - 9.4, sebanyak 29 item obat $(46,03 \%)$ dari total item obat. 
Kelompok C : dengan NIK 4 - 6.4, sebanyak 28 item $(44,44 \%)$ dari total item obat.

Hasil analisis ABC Indeks Kritis dapat dilhat pada Tabel 4.

Tabel 4. Pengelompokkan Obat dengan Analisis ABC Indeks Kritis

\begin{tabular}{ccc}
\hline Kelompok & $\begin{array}{c}\text { Jumlah Item } \\
\text { Obat }\end{array}$ & Persentase (\%) \\
\hline A & 6 & 9,52 \\
B & 29 & 46,03 \\
C & 28 & 44,44 \\
\hline Jumlah & 63 & 100 \\
\hline
\end{tabular}

Berdasarkan analisis $\mathrm{ABC}$ Indeks Kritis yang dilakukan, diketahui bahwa yang termasuk dalam kelompok A dengan NIK 9.5 - 12 sebesar 9,52\% dari total item obat. Pengendalian persediaan obat pada kelompok ini harus diperhatikan, agar terhindar dari kekosongan mengingat kemanfaatannya dalam terapi sangat dibutuhkan. Selain itu, nilai investasi yang tinggi turut menjadi pertimbangan. Nilai investasi yang cukup besar jika dikelola dengan baik, maka akan memberikan keuntungan bagi rumah sakit, sebaliknya pengelolaan yang kurang baik akan menimbulkan kerugian. Pemesanan dapat dilakukan dalam jumlah sedikit dengan frekuensi lebih sering. Hal yg dapat dilakukan dalam mengontrol persediaan obat kelompok $A$ yaitu dengan melakukan pemantauan setiap hari atau setiap minggu. Perencanaan yang dilakukan harus akurat dan menggunakan data terbaru. Pemilihan supplier juga harus memperhatikan waktu tunggu, sehingga terhindar dari kekosongan obat (Reddy, 2008).

Kelompok B dengan NIK 6.5 - 9.4 (46,03\%) merupakan item obat dengan kekosongan yang dapat ditolerir tidak lebih dari 48 jam. Pemesanan dapat dilakukan dengan frekuensi lebih jarang dengan jumlah relatif lebih banyak. Kontrol terhadap item obat ini juga tidak terlalu ketat. Begitu pula pada kelompok $\mathrm{C}$ dengan NIK 4 - 6.4 (44,44\%) merupakan kelompok item obat yang kekosongannya dapat ditolerir lebih dari 48 jam. Frekuensi pemesanan kelompok obat ini lebih jarang dan pengawasan juga lebih longgar. Item obat dalam kelompok ini dalam pengadaannya disesuikan dengan dana yang tersedia. Jika dana terbatas maka item obat dalam kelompok ini yang menjadi prioritas untuk dikeluarkan dari daftar perencanaan dan pengadaan obat. Pengurangan obat dapat dilakukan dengan memperhatikan kandungan bahan aktif obat untuk menghindari variasi obat yang teralu banyak (Priatna, 2010). Dalam penelitian yang dilakukan oleh Purwaningrum (2001), dikatakan bahwa metode analisis ABC Indeks Kritis merupakan pilihan yang tepat dalam menentukan prioritas pengadaan dan pengawasan penggunaan obat, terutama bagi rumah sakit yang memiliki keterbatasan dana dan sumber daya manusia.

Beberapa permasalahan yang ditemukan terkait pengelolaan obat yang kurang efektif antara lain terjadinya kekosongan obat, pembelian ke apotek luar, dan pembelian tidak yang terencana. Melalui analisis ABC Indeks Kritis ini, diharapkan adanya perbaikan dalam perencanaan dan pengadaan obat antibiotik di Rumah Sakit Advent Manado sehingga terjadi efisiensi penggunaan dana dan diperoleh hasil terapi yang optimal bagi pasien

\section{Kesimpulan}

Berdasarkan penelitian yang dilakukan, dapat disimpulkan bahwa dari total 63 item obat antibiotik, 6 item merupakan kelompok A (9,52\%), 29 item merupakan kelompok B (46,03\%), dan 28 item merupakan kelompok C (44,44\%). Metode ABC Indeks Kritis dapat membantu rumah sakit dalam melakukan perencanaan dan pengadaan obat secara efisien dengan mempertimbangkan nilai pakai, nilai investasi dan nilai kritis obat.

\section{Daftar Pustaka}

AMRIN - Study Group. 2005. Penggunaan Antibiotik di RS Dr Soetomo Surabaya dan RSUP Dr. Kariadi Semarang.

Brahma, Marak, et al. 2012. Rational Use of Drug and Irrational Drug Combination. The Internet Journal of Pharmacologi 10:1.

Febriawati, H. 2013. Manajemen Logistik Farmasi Rumah Sakit. Gosyen Publishing, Yogyakarta.

Kartika, F., Harsono, S.B., dan Sarimanah, J. 2014. Analisis Penggunaan Antibiotik Pada Pasien Rawat Inap Deman Tifoid (ICD A01.0) Di Rumah Sakit Umum Daerah Kabupaten Sukoharjo Tahun 2013 Dengan Metode ATC/DDD. Jurnal Farmasi Indonesia 2 (11) : 158-167.

Permenkes RI. 2016. Peraturan Menteri Kesehatan Republik Indonesia Nomor 72 Tahun 2016 tentang Standar Pelayanan Kefarmasian di Rumah Sakit. Jakarta: Departemen Kesehatan.

Priatna, H. 2010. Analisis Perencanaan dan Pengendalian Obat Kelompok A Pada Analisis ABC di RS Melati Tangerang Tahun 2009. FKM UI, Depok.

Purwaningrum, Y. 2001. Perencanaan Kebutuhan Obat di Bagian Administrasi Logistik Kesehatan Rumah Sakit Pusat Angkatan Darat Gatot Soebroto Jakarta. FKM UI, Depok.

Reddy,V.V. 2008. 'Hospital Material Management' Dalam Managing a Modern Hospital (2 $2^{\text {nd }}$ ed), oleh A.V Srinivasan (ed), 126-143. Sage Publication, New Delhi.

Suciati, S dan Adisasmito, W.B. 2006. Analisis Perencanaan Obat Berdasarkan ABC Indeks Kritis di Instalasi Farmasi. Jurnal Manajemen Pelayanan Kesehatan 09 (2006): 19-26 